\title{
Orientalismo en la poesía de Rubén Darío y otros poetas latinoamericanos
}

Recibido: 20.09.2017 / Aprobado: 10.10.2017

Por Jorge Román-Lagunas ${ }^{1}$

\section{Resumen}

Jorge Román Lagunas, explora los vasos comunicantes entre la poesía de oriente y sus influencias en la poesía latinoamericana, en el contexto de la constante globalización del capitalismo, la imposición y diseminación de una ideología colonialista eurocéntrica, a través del desarrollo de las comunicaciones pero que se enfrenta a los atisbos de una conciencia de identidad cosmopolita incluyente en la literatura modernista hispanoamericana.

El autor hace una crítica a los que liviana y festinadamente despachan la apetencia de Rubén Darío por el conocimiento de oriente, como meras chinerías, para postular a Darío y a los poetas modernistas y postmodernistas latinoamericanos como artistas investigadores curiosos de la cultura universal.

Palabras claves: Orientalismo modernismo colonialismo eurocentrismo poesía identidad.

\begin{abstract}
Jorge Román Lagunas, explores communicating vessels between the poetry of the East and its influences in Latin American poetry, in the context of the constant globalization of capitalism, the imposition and dissemination of a Eurocentric colonialist ideology, through the development of communications, but is facing the glimpses of an inclusive cosmopolitan identity consciousness in Hispanic-American modernist literature.
\end{abstract}

The author makes a criticism of those who lightly and fiercely dispel Ruben Darío's appetite for Oriental knowledge, as mere chinoiserie, to postulate to Dario and the Latin American modernist and postmodernist poets as curious researchers of universal culture.

Key words: Orientalism, modernism, colonialism, eurocentrism, poetry, identity.
Si para los europeos el Descubrimiento y la Conquista de América significó expansión y cristianización, desde la perspectiva de los indígenas, Descubrimiento y Conquista significó supresión e imposición. El periodo de Colonización duró desde 1942 hasta aproximadamente 1810, cuando la mayoría de los países latinoamericanos obtuvo la Independencia política. El proceso comenzó en 1776, cuando los EstadosUnidosobtuvieronsu propia Independencia y continuó hasta

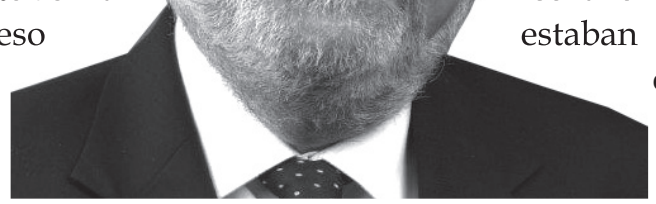

Dr. Jorge Román-Lagunas.
1898, cuando Cuba se liberó de España. Después de obtener la independencia política, muchos intelectuales latinoamericanos comenzaron a exigir la "verdadera independencia", la que algunos llamaron "independencia mental". En el caso de la expresión literaria, esta actitud independentista significó en cierta forma el rechazo de la literatura española (aunque estaban escribiendo en español), así como el deseo de liberarse de esa área de influencia: adoptaron otros modelos europeos. La adopción de modelos

$1 \mathrm{PhD}$. Catedrático Titular de Literatura y Cine Latinoamericano (Purdue University Northwest). Conferencista internacional. Ha publicado 9 obras, aproximadamente 45 artículos en revistas especializadas de Europa, Estados Unidos, Centroamérica y Sudamérica. Fundador y Director de revistas especializadas. 
franceses e ingleses ayudó al surgimiento de la reacción Mundonovista, una tendencia literaria cuyo principal objetivo principal fue retratar lo aborigen, como lo dice su propio nombre Mundo Nuevo. Si observamos esta tendencia mundonovista desde la perspectiva americana, todavía esta reacción contra el europeísmo muestra supresión e imposición. Esto es evidente en la religión y el lenguaje: hay "notas" nativas $\mathrm{o}$ indígenas, como adiciones exóticas al catolicismo y a la lengua española. Pero todavía prevalece la supresión.

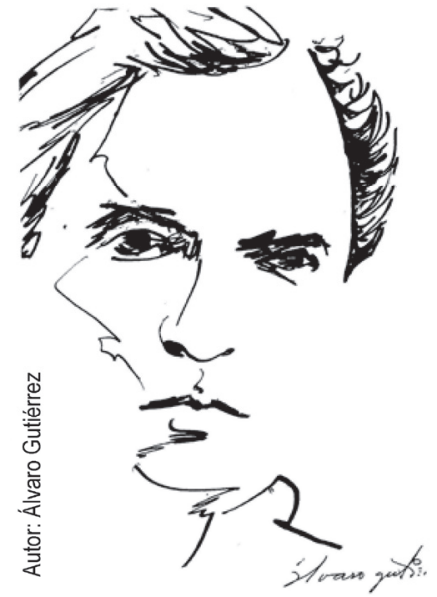

Tan profunda fue esta supresión/ imposición, que en las enseñanzas de la historia literaria se nos muestra el interés de algunos escritores en culturas no europeas, sólo a través de la literatura europea. Estas enseñanzas se aplican a todo escritor que muestra interés en la filosofía oriental, que pone en escena un pasaje o un retrato oriental, que introduce personajes y lugares de Oriente, y aún más notable se aplica a cada escritor que adopta una visión de mundo orientalista.

Como prueba de esta imposición eurocéntrica, que domina la mentalidad de historiadores y críticos literarios, hemos decidido analizar brevemente el caso de la poesía del mexicano José Juan Tablada que vivió entre 1871 y $1945 .^{2}$ En 1920 Tablada público su libro LI PO Y OTROS PPOEMAS. Desde la publicación de este libro la crítica ha señalado que las referencias y las paráfrasis a $\mathrm{Li}$ Po, llegan a Tablada a través de la poesía de Apollinaire o de tendencias avantgarde, como el cubismo. Hasta 1983, tal como señala la profesora Adriana García de Aldridge ${ }^{3}$ nadie había examinado la relación entre la poesía de Tablada y la cultura china tradicional, y nadie había notado que algunos de estos poemas de Tablada son una traducción de poemas de Li Po, y que otros poemas de Tablada son figuras parafrásticas del imaginario poético de Li Po.

El mismo Tablada respondiendo a sus críticos ha señalado que su poesía es "totalmente diferente a la de Apollinaire". Aun después de esta aclaración, la crítica continúo insistiendo en que Tablada escribía sus ideogramas, siguiendo el modelo francés. Solo en 1983 la profesora García de Aldridge descubrió que los experimentos tipográficos (o sea los ideogramas) de Tablada venían de una sola fuente: la tradición China, y no de la poesía francesa.

Una breve mirada al caso de las imágenes orientales del poeta nicaragüense Rubén Darío también ayuda a afirmar nuestra teoría de la imposición eurocéntrica. Es lugar común de los críticos literarios la afirmación de que las imágenes orientales de cierta poesía de Darío son nada más que el resultado de una actitud poética exótica o escapista, y que no están incorporadas ni como parte secundaria o lateral de su poética, ni mucho menos al meollo de poética. Del mismo modo, es lugar común de la critica la expresión "chinerías", un término algo despectivo para referirse al interés orientalista de Darío y de otros poetas latinoamericanos.

Resulta interesante relacionar la temprana predilección de Darío por una visión de mundo sincrética, "en la cual el poeta vincula en una unidad a Sócrates, Cristo, Visnú, Buda y Brahma Esta unidad forma una fuerza espiritual que está siendo destruida por la fuerzas de la razón". ${ }^{4}$

Al contemplarte augusta, te venero Al ver tu lux mi corazón se inflama Pues al fulgor de tu radiosa llama Se estremece la faz del mundo

Cayó la fe con su terrible fuero Ya tu voz por doquiera se derrama Se hunden Cristo, Vichnú, Buda y Brahma $\mathrm{Y}$ las naciones van por tu sendero

\footnotetext{
El orientalismo de Tablada puede ser estudiado en cuatro de sus libros: El Florilegio (1899), Li Po y otros poemas (1920), Un día (1919), y El jarro de flores (1920). Adriana García de Aldridge: "Las fuentes chinas de Juan Jose Tablada". Bulletin of HispanicStudies. Vol. LX (1983), 109-119.

Cathy Login Jrade "Ruben Dario and the Romantic search for unity. The Modernist Reecourse to Esoteric Tradition". University of Texas Press, $1983,108$.
} 
Una segunda observación es el interés de Darío en la doctrina de la reencarnación, mirada, esclaro, desde un punto de vista más objetivo y menos eurocéntrico. Este interés de Darío es con frecuencia atribuido a su interés por lo esotérico, visto como un pecadillo de juventud. Enrique Anderson Imbert, unos de los más respetados historiadores de la literatura latinoamericana, señala que "Darío se imaginaba un tiempo metafísico. Sus lecturas teosóficas, esotéricas, ocultistas, lo habían iniciado en la idea de pre existencias, de reencarnaciones, de tiempos cíclicos y eternos retornos". ${ }^{5}$ Anderson Imbert presume que el interés de Darío por la reencarnación viene de lecturas esotéricas y ocultistas, equivocándose al ni siquiera visualizar la posibilidad del interés del poeta por el Budismo. Cathi Login Jrade señala que"la religión oriental y el pitagorismo llegan a fusionarse en ciertas sectas esotéricas y en la imaginación poética de escritores del periodo". Para nosotros es claro que Anderson Imbert se limitó a aceptar el interés de Darío por la reencarnación como algo secundario, algo que el poeta leyó en libros esotéricos, en vez de observar una legítima fusión de budismo (la reencarnación) y pitagorismo (la armonía de las esferas, la eterna recurrencia de las cosas) en el centro de su imaginación poética.

No podemos ver su poema "Reencarnación", escrito cuando el poeta tenía 23 años, como un mero y juvenil ejercicio esotérico. Tras la aparente simplicidad formal, escuchamos una voz poética que llega a reconocer sus existencias previas, "poniéndolas en contacto (se refiere a sus existencias previas) con su permanente ego, con el ánima divina, en la cual sobrevive cada

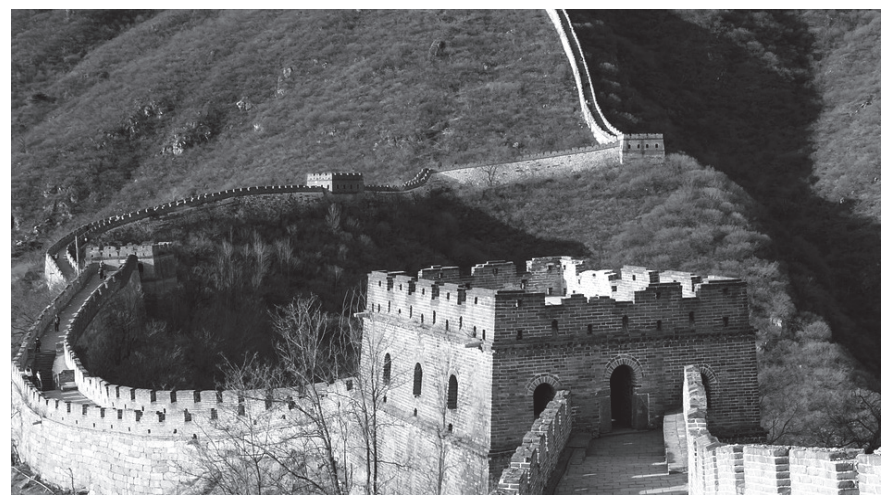

Pixabay.com personalidad, dejando una impresión eterna en su ser, que se reencarna permanentemente". ${ }^{6}$

\section{REENCARNACIÓN}

Yo fui coral primero

Después hermosa piedra

Después fui de los bosques verdes y colgante hiedra

Después yo fui manzana,

Lirio de campiña

Labio de niña

Una alondra cantando en la mañana

$Y$ ahora soy un alma

Que canta como canta una palma

De luz de Dios al viento

El coral, la piedra, la hiedra, la manzana, el lirio, el labio de niña, una alondra, son las sucesivas reencarnaciones del ser, el que llega a los umbrales de la divinidad, escapando del ciclo de la reencarnación, para llegar a ser fuego divino, para pasar del Karma a la Nirvana.

Como hemos visto, la visión de mundo sincrética de Darío, y su creencia en la reencarnación se encuentran ya en su producción temprana, pero siguen presentes o latentes a través de su extensa obra. Nos parece que su visión sincrética incluye un componente budista, y que su creencia en la reencarnación muestra una directa relación con el budismo: esta doctrina ensena que en un mundo interconectado, todas las acciones tienen consecuencias (a esto le llaman Karma), las consecuencias de las acciones

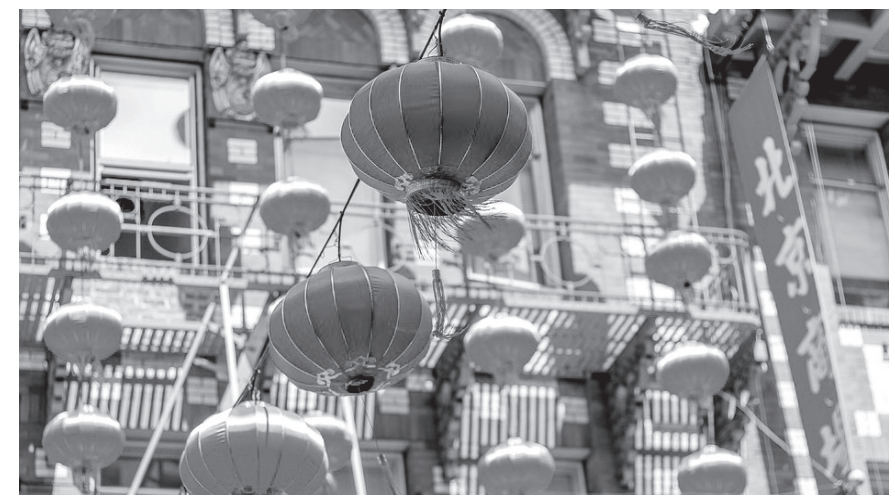

Pixabay.com

5 Enrique Anderson Imbert:" La originalidad de Rubén Darío" Buenos Aires, Centro Editor de América Latina, 1967.

6 Cathy Logan Jrade, 53. 


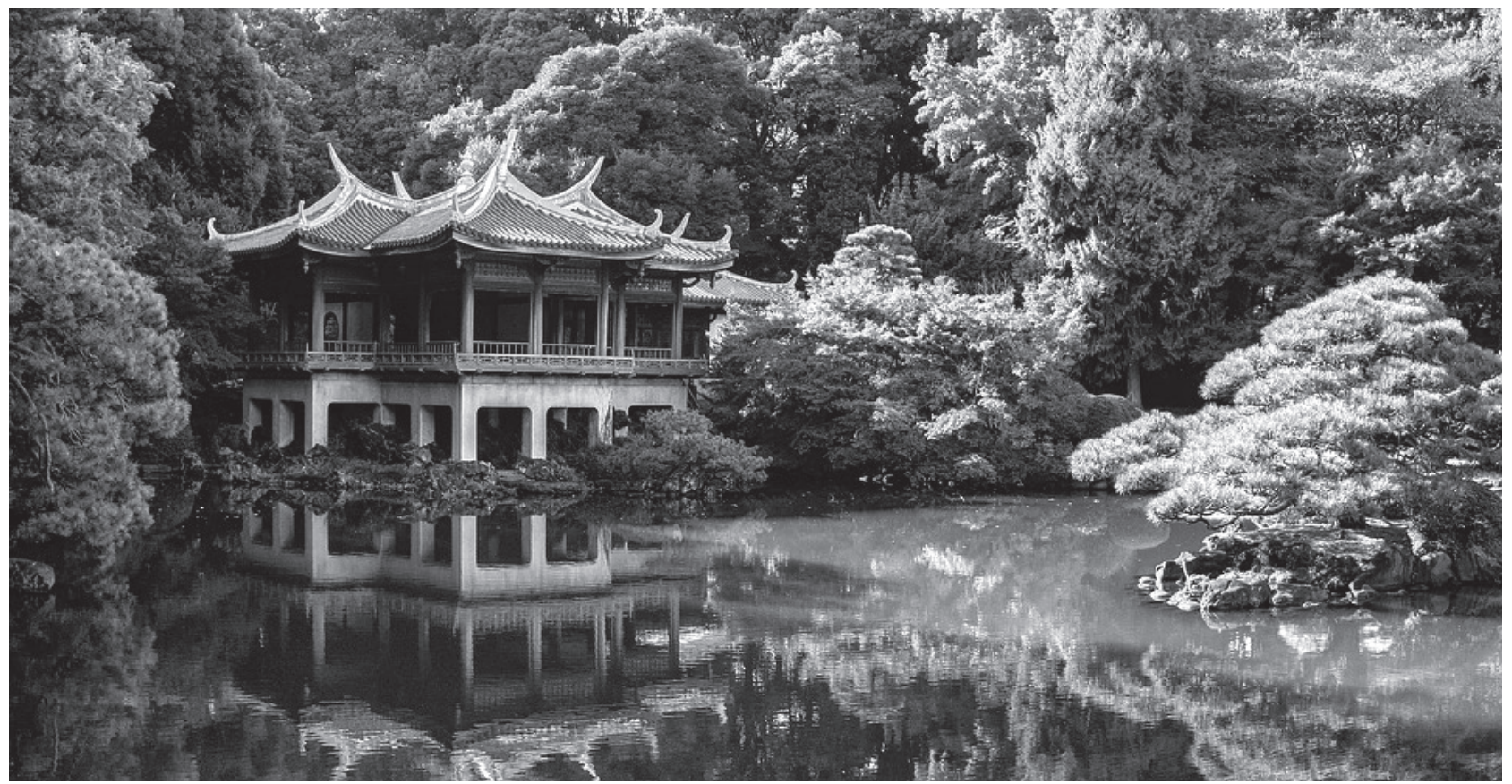

Pixabay.com

en esta vida, como en las vidas anteriores, se sentirán en las vidas futuras, y este proceso es la reencarnación. El budismo enseña que por medio del estudio y la meditación se puede escapar del ciclo de volver a nacer, para llegar a Nirvana (la luz de Dios, en el poema de Darío).

Hemos examinado brevemente como la crítica literaria no ha reconocido el auténtico interés de Tablada y Darío en la filosofía y región orientales y que descartaron este interés como escapismo, exotismo, como algo que no se relaciones con el meollo de sus poéticas.

Pero Tablada y Darío no son los únicos cuyo orientalismo ha sido soslayado como un adorno. Tomemos el caso del cubano Julián del Casal, poeta modernista al referirse a sus poemas de motivos japoneses ("Kakemono" y" Sourimono") un historiador literario señala que:

Su exotismo y ansia de evasión lo llevó al culto de todo lo/ japonés, $y$

Su habitación estaba llena de artículos de ese país, incluyendo/ su bata

De casa y la sobrecama. Es su época de su gran admiración/ por el

Marfil, el sándalo, el crisantemo y de sus poemas Kakemono y/ Sourimono. ${ }^{7}$

En esta cita vemos claramente primero: su orientalismo no se toma en serio, y sin justificación, se reduce a muebles y adornos; segundo: los poema de Casal se enumeran en la misma serie de objetos de origen oriental, disminuyendo así su valor artístico, llegando al extremo de nombrar los poemas junto una bata de casa y una sobrecama. En este punto hay que destacar que este historiador se complace ensenándonos la influencia de muchos poetas franceses, españoles, alemanes:

El libro de iniciación de Casal es "Hojas al viento" (1890)/ mezcla de

Maticesrománticos y parnasianos: de influencias españolas y / francesas.

Hay eminiscencias de los españoles Zorrilla, Bécquer,/ Campoamor,

Batrina, Núñez de Arce junto a las de Gautier,/ 


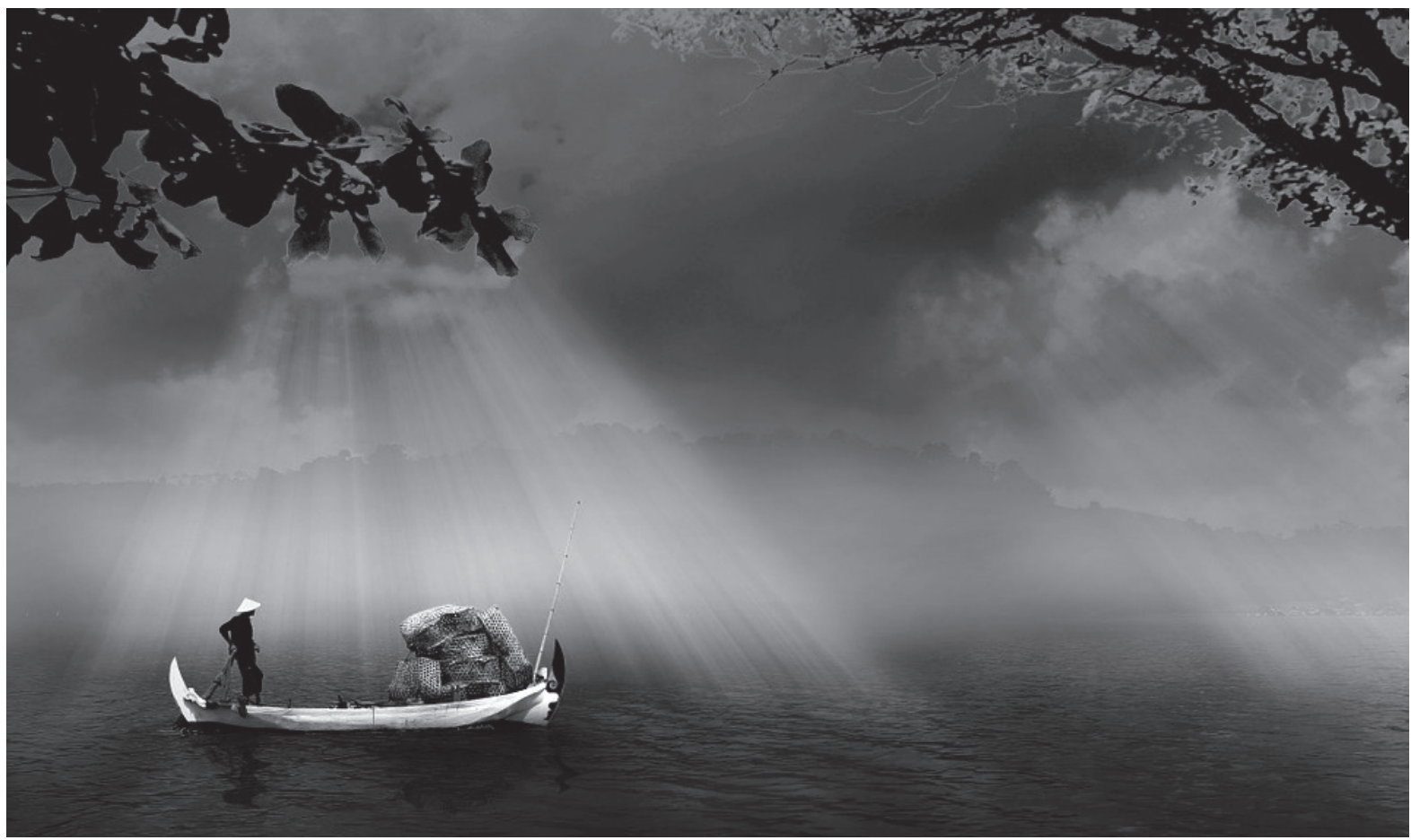

Pixabay.com

Baudelaire, Goppee...

Hay también en estos versos del comienzo algo de Heine y Leopardi. ${ }^{8}$

La cantidad de poetas europeos citados por este historiador va demasiado lejos: incluye poetas importantes de Francia, España, Francia, Alemania e Italia, pero también incluye poetas bastantedesconocidos, aun para especialistas. Esto demuestra un notable nivel de conocimiento sobre la poesía europea. Por otra parte, cuando el historiador se encuentra con poemas orientalistas (en este caso de motivos japoneses), disminuye su importancia, demostrando claramente su propio desconocimiento de la cultura y literatura japonesas. Similar desconocimiento padece la mayoría de los críticos latinoamericanos: es fácil descubrir influencias en nuestros poetas provenientes de literaturas extranjeras que conocemos, pero no por eso debemos desestimar las influencias que vienen de poetas de culturas que desconocemos.

Una lista mínima de poetas cuyo Orientalismo debe ser estudiado incluye a Tablada, Darío y Casal. A ellos hay que agregar Efrén Rebolledo, poeta mexicano autor de "Rimas japonesas" (1909), "Nikko" (1910) y "Hojas de Bambú" (1920), al argentino Leopoldo Lugones, que en su libro "Las horas doradas" (1922) incluye un hermoso poema titulado "Estampa japonesa", y el colombiano Guillermo Valencia que tradujo y parafraseo poemas chinos del siglo VIII al XX en su libro "Catay" (1929).

Como dijimos Tablada introdujo el Haiku en la poesía latinoamericana, ${ }^{9}$ pero varios poetas siguieron con esa tradición: entre ellos Jorge Luis Borges y los mexicanos Carlos Pellicier, Xavier Villaurrutia y José Gorostiza.

Varios sudamericanos también han escrito un número significativo de poemas con motivos orientales o como resultado de sus experiencias de viajes a Oriente. El ecuatoriano Jorge Carrera Andrade publico Microgramas en 1940, un libro dedicado al estudio y antología de Haikus; Pablo Neruda, en sus tres volúmenes de Residencia en la tierra (Volumen I y II, 1935; volumen 3, 1947), muestra un vuelco desde una visión neo-

$8 \quad$ Orlando Gomez Gil, 416.

9 Recomendamos dos artículos: el de García de Aldridje ya citado, y el de Klaus Meyer-Minnemann: "Formas de escritura ideográfica en 'Li Po y otros poemas de J.J.

Tablada': Nueva Revista de Filología Hispánica, vol. 36, No. 1 (1988), 433-453. 


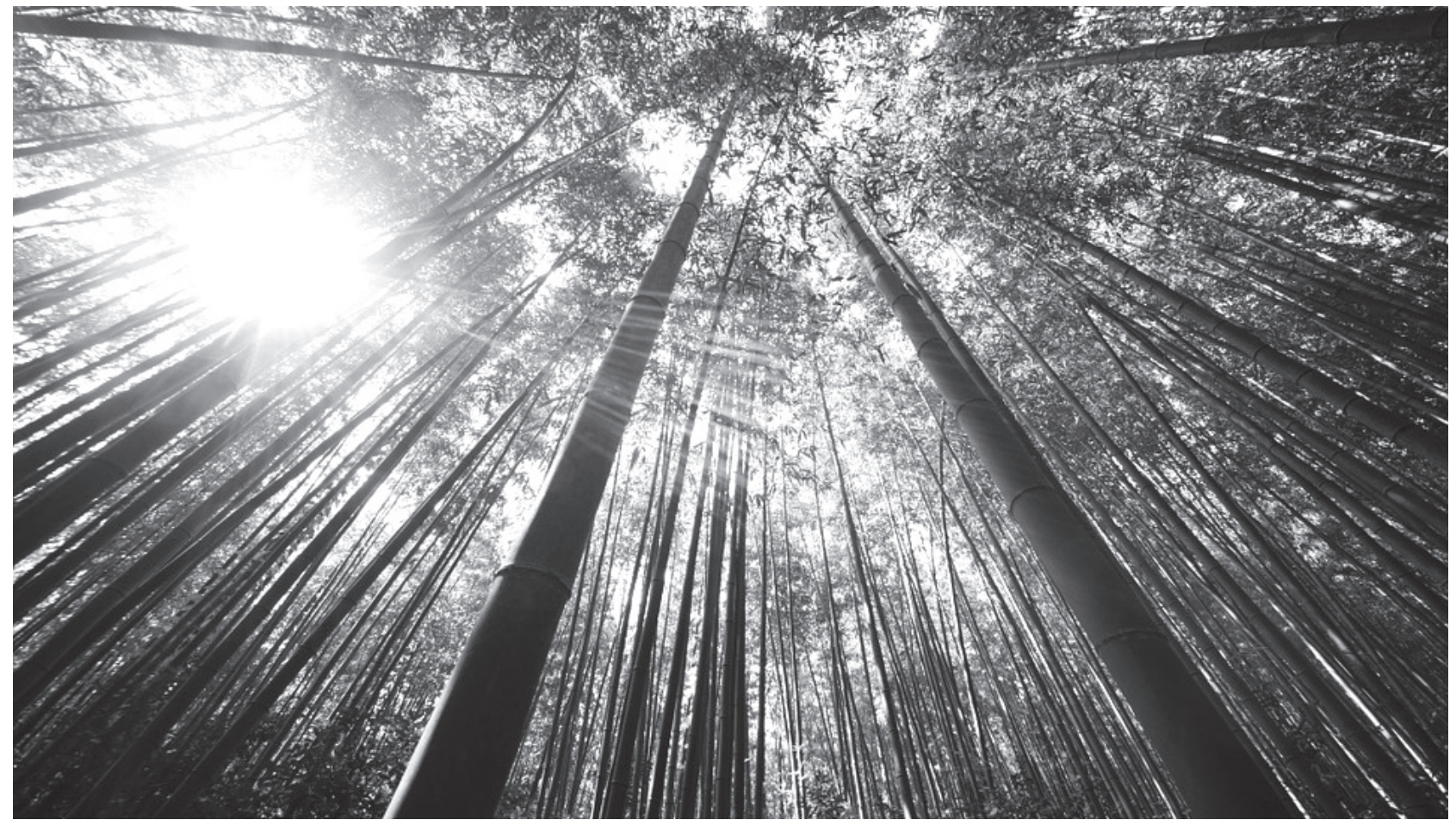

Pixabay.com

romántica con un canto extrovertido y erótico, a una poesía agudamente introvertida, en la cual la voz poética describe, paso a paso lo que podríamos llamar el viaje interior, la búsqueda del ser oculto en sí mismo. Otro chileno, Efraín Barquero, publica en 1973 su poemario "El viento de los reinos", dedicado a su experiencia en China, un esfuerzo honesto y profundo por entender y comunicarse con la filosofía oriental, mostrado una suerte de veneración por esas creencias milenarias.

Finalmente, es necesaria una referencia a la obra poética y ensayística de Octavio Paz. Como lo plantea en su libro "Puertas al campo", Paz cree firmemente en el origen asiático de los indígenas de América Latina, al mismo que tiempo encontramos profundas huellas orientales en su obra poética. Este aspecto lo ha estudiado Julia Kushigian en su obra "Orientalismo en la tradición literaria hispánica: en un dialogo con Borges, Paz y Sarduy" (1991). Desde el concepto budista del salto a la otra orilla que encontramos en su poema "La otra orilla", hasta la imagen del jardín floreciente de la colección de poemas "Ladera Este. Y cito a Julia Kushigan; "se puede decir que la intención tacita, o si se prefiere, la intuición subliminal apunta a la confrontación de dos jardines: el oriental y el mexicano, ambos sabios y secretos. Paz ha adoptado conscientemente su condición de hombre de dos mundos y ha dado su respuesta al declarar "No hay más jardines que los que llevamos adentro " $\mathrm{Al}$ creer en el origen oriental del indígena americano, sus imágenes poéticas muestran la agonía (en el sentido de "lucha") entre la afinidad y la oposición de estos dos elementos (Oriente/Occidente americano). Su visión poética refleja el ritmo separación/unión, el que proviene de la concepción cosmológica de la Antigua China. ${ }^{10}$

No es asunto secundario el hecho de que numerosos poetas nuestros hayan encontrado por distintos caminos, una afinidad filosófica con lo oriental, o una identificación con doctrinas milenarias distintas a la tradición judeo-cristiana. Y es asunto notable que tres de los más grandes poetas latinoamericanos hayan caminado esos senderos: me refiero, por cierto a Rubén Darío, Pablo Neruda y Octavio Paz.

10 Esta observaciones sobre Octavio Paz siguen de cerca partes de A. Kushigian: Orientalism in the Hispanic Literary Tradition: in Dialogue with Borges, Paz and Sarduy". University of Texas Press, 1991. 